\title{
Prognostic and clinical significance of HOXC9 and HOXD10 in papillary thyroid cancer
}

\author{
Yi-Ming Cao ${ }^{1,2}$, Duo Wen ${ }^{1,2}$, Ning Qu ${ }^{1,2}$, Yong-Xue Zhu ${ }^{1,2}$ \\ ${ }^{1}$ Department of Head \& Neck Surgery, Fudan University Shanghai Cancer Center, Shanghai, China; ${ }^{2}$ Department of Oncology, Shanghai Medical \\ College, Fudan University, Shanghai, China \\ Contributions: (I) Conception and design: YM Cao; (II) Administrative support: YX Zhu; (III) Provision of study materials or patients: YX Zhu; (IV) \\ Collection and assembly of data: D Wen; (V) Data analysis and interpretation: YM Cao; (VI) Manuscript writing: All authors; (VII) Final approval of \\ manuscript: All authors. \\ Correspondence to: Yong-Xue Zhu. Department of Head \& Neck Surgery, Fudan University Shanghai Cancer Center, Shanghai 200032, China; \\ Department of Oncology, Shanghai Medical College, Fudan University, Shanghai 200032, China. Email: zhuyongxue163@126.com.
}

\begin{abstract}
Background: The homebox superfamily play an important role in tumorigenesis. HOXC9 and HOXD10 were reported playing critical roles in tumor progression in many malignant tumors. This study aimed to research the expression of HOXC9 and HOXD10 in papillary thyroid cancer, and to verify the prognostic and clinical significance of HOXC9 and HOXD10.

Methods: Immunohistochemistry was used to determine the expression of HOXC9 and HOXD10 in 98 pairs of papillary thyroid cancer and paracancer tissues. Clinicopathologic data were collected and analyzed to verify the prognostic and clinical significance of HOXC9 and HOXD10.

Results: The expression of HOXC9 and HOXD10 decreased in papillary thyroid cancer. The low expression of HOXC9 was associated with Hashimoto's thyroiditis and lymph node metastasis $(\mathrm{P}<0.05)$. The low expression of HOXD10 was associated with extrathyroidal extension and lymph node metastasis $(\mathrm{P}<0.05)$. The co-expression rates of HOXC9 and HOXD10 was $44.90 \%$. The low expression of both HOXC9 and HOXD10 was associated with lymph node metastasis $(\mathrm{P}<0.05)$.

Conclusions: The expression of HOXC9 and HOXD10 was downregulated in papillary thyroid cancer. Low expression of HOXC9 and HOXD10 might be related to the malignancy of papillary thyroid cancer. HOXC9 and HOXD10 may be used as diagnostic and prognostic biomarkers in the future.
\end{abstract}

Keywords: Papillary thyroid cancer (PTC); HOXC9; HOXD10; clinical significance

Submitted Mar 01, 2021. Accepted for publication Mar 24, 2021.

doi: $10.21037 /$ tcr-21-373

View this article at: https://dx.doi.org/10.21037/tcr-21-373

\section{Introduction}

Thyroid cancer is the most common endocrine tumor in humans. The incidence of thyroid cancer has increased recently because of the improving diagnostic approach. Papillary thyroid cancer (PTC) is a major type (80-85\%) of thyroid cancer (1). The clinical biological behavior of PTC is relatively inert, and the 10-year survival rate can reach more than $90 \%$ after reasonable treatment. However, due to its anatomical location (adjacent to trachea, esophagus, laryngeal recurrent nerve, parathyroid and other important organs), a considerable number of patients with advanced or recurrent PTC cannot obtain good surgical effect, but also have to face serious postoperative complications and organ function loss (2). Although the prognosis of PTC is optimistic, the recurrence rate was relatively high after a 15-year follow-up. And a small group of PTC patients seem to have higher risk of metastasis and recurrence (3-5). Therefore, early diagnosis and screening of high-risk population has always been the key to the prevention and 
treatment of PTC. The understanding of the pathogenesis of PTC is the basis to assist clinicians in population risk assessment and early diagnosis.

The homebox (HOX) superfamily play an important role in cell differentiation and morphogenesis. The dysregulation of HOX gene can affect various pathways and result in tumorigenesis and metastasis (6,7). Many HOX genes have been found to be expressed aberrantly, that influence the biological behavior and prognosis of many cancers (8-11). Our previous studies found HOXC9 and HOXD10 were aberrantly hypermethylated through Methyl-Seq and quantitative methylation-specific PCR (Q-MSP) in PTC $(12,13)$. HOXC9 and HOXD10 were reported to play critical roles in tumor progression and to be associated with poor prognosis in many malignant tumors like colorectal cancer, gastric cancer, breast cancer and neuroblastoma (14-17). Their functions as tumor suppressors were primarily verified in vitro. However, the expression of HOXC9 and HOXD10 and their biological significance have not been identified in PTC. This study aims to investigate the expression and clinical significance of HOXC9 and HOXD10 in PTC. We present the following article in accordance with the REMARK reporting checklist (available at http://dx.doi.org/10.21037/tcr-21-373).

\section{Methods}

\section{Clinical samples}

Totally 98 PTC patients were enrolled in this study. The inclusion criteria were patients who received initially surgery by designated physicians at the Department of Head and Neck Surgery, Fudan University, Shanghai Cancer Center (Shanghai, China) from January 2015 to December 2017. All of the patients were pathologically confirmed as PTC. Patients who had undergone previous thyroidectomy or revision neck dissection were excluded. Tumors less than $3 \mathrm{~mm}$ were too small to get enough samples, were also excluded. Lobectomy and isthmectomy was performed in T1 and T2 tumor confined to unilateral lobes. Total thyroidectomy was performed in T3 and T4 tumor or some of the patients with high risk factors. These risk factors include multifocal cancer, lymph node metastasis, distant metastasis, family history, and early exposure to ionizing radiation. Total thyroidectomy is also feasible in some cases where postoperative radionuclide therapy is considered necessary. Central neck dissection was performed in $\mathrm{cN} 1$ and most of $\mathrm{cN} 0$ patients. Additional modified lateral lymph node dissection was performed in patients with clinically suspicious lateral lymph node metastasis (cN1b). The clinicopathological data of these patients enrolled are summarized in Table 1. The tumor-node-metastasis (TNM) stages were according to the American Joint Cancer Committee (AJCC) TNM grading system (8th ed. 2017). The study was conducted in accordance with the Declaration of Helsinki (as revised in 2013). The study was approved by ethics board of Fudan University Shanghai Cancer Center (No.: 050432-4-1911D) and informed consent was taken from all the patients.

\section{Immunobistochemistry (IHC)}

IHC was performed according to a standard protocol. Briefly, paraffin-embedded samples were cut into 4- $\mu \mathrm{m}$ sections and placed on polylysine-coated slides. Paraffin sections were baked overnight at $60^{\circ} \mathrm{C}$, deparaffinized in xylene, rehydrated through graded ethanol, quenched for endogenous peroxidase activity in $0.3 \%$ hydrogen peroxide at $37^{\circ} \mathrm{C}$ for $15 \mathrm{~min}$, and processed for antigen retrieval by high pressure cooking in citrate antigen retrieval solution for $10 \mathrm{~min}$. Sections were incubated at $37^{\circ} \mathrm{C}$ for $1.5 \mathrm{~h}$ with mouse monoclonal antibodies against HOXC9 (1:200; Abcam, Cambridge, MA, USA) and HOXD10 (1:1,000; Abcam, Cambridge, MA, USA) in a moist chamber. Immunostaining was performed using the DAB substrate kit (ab64238, Abcam, Cambridge, MA, USA), which resulted in a brown-colored precipitate at the antigen site. Then, the sections were counterstained with hematoxylin and mounted in a non-aqueous mounting medium. All the repetitions included a no primary antibody control.

The staining intensity was scored as 0 (low, -), 1 (weak, +), 2 (medium, ++) or 3 (strong, +++). The extent of staining was scored as $(0,<5 \% ; 1,5-25 \% ; 2,26-50 \%$; and $3,>50 \%)$ according to the percentages of the positive staining areas in 5 random high-power fields. Scores for staining intensity and staining extent were then multiplied to obtain the final immunoreactivity score for each case. Tumors with a final immunoreactivity score of $<3$ were considered to be low (-), and those with a final immunoreactivity score of $\geq 3$ were considered to be high $(+)(18)$.

\section{Statistical analysis}

Statistical analyses were performed using Student's $t$-test, paired $t$-test, and Chi-square test. The odds ratios (ORs) for the relationships between each variable and the expression 
Table 1 Clinical characteristic of all patients

\begin{tabular}{|c|c|}
\hline Characteristic & Value \\
\hline Patients number & 98 \\
\hline Age & $43.12 \pm 12.997$ \\
\hline$<55$ years & $74(75.5)$ \\
\hline$\geq 55$ years & $24(24.5)$ \\
\hline \multicolumn{2}{|l|}{ Gender } \\
\hline Male & $25(25.5)$ \\
\hline Female & $73(74.5)$ \\
\hline \multicolumn{2}{|l|}{ Invasion } \\
\hline Yes & $19(19.4)$ \\
\hline No & $79(80.6)$ \\
\hline Size & $1.455 \pm 0.9836$ \\
\hline$>1 \mathrm{~cm}$ & $43(43.9)$ \\
\hline$\leq 1 \mathrm{~cm}$ & $55(56.1)$ \\
\hline \multicolumn{2}{|l|}{ Multifocal } \\
\hline Yes & $26(26.5)$ \\
\hline No & $72(73.5)$ \\
\hline \multicolumn{2}{|l|}{ Bilateral } \\
\hline Yes & $16(16.3)$ \\
\hline No & $82(83.7)$ \\
\hline \multicolumn{2}{|c|}{ Hashimoto's thyroiditis } \\
\hline Yes & $12(12.2)$ \\
\hline No & $86(87.8)$ \\
\hline \multicolumn{2}{|c|}{ Lymph node metastasis } \\
\hline Yes & $54(55.1)$ \\
\hline No & $44(44.9)$ \\
\hline \multicolumn{2}{|l|}{ TNM stage } \\
\hline I & $86(87.8)$ \\
\hline II & $11(11.2)$ \\
\hline III & $1(1.0)$ \\
\hline IV & $0(0.0)$ \\
\hline
\end{tabular}

Data are presented as $\mathrm{n}(\%)$ or mean \pm standard deviation.

of HOXC9 and HOXD10 were calculated by univariate logistic regression analysis. All confidence intervals (CIs) were stated at the $95 \%$ confidence level. A P value of $<0.05$ was considered to be statistically significant. SPSS 19.0 was
Table 2 The expression of HOXC9 and HOXD10 in PTC tissues and adjacent tissues

\begin{tabular}{lcc}
\hline Low expression & HOXC9, $\mathrm{n}(\%)$ & HOXD10, n (\%) \\
\hline PTC tissues & $40(40.8)$ & $33(33.7)$ \\
Adjacent tissues & $24(24.5)$ & $16(16.3)$ \\
$\chi^{2}$ & 7.864 & 5.939 \\
P value & $<0.05$ & $<0.05$ \\
\hline
\end{tabular}

PTC, papillary thyroid cancer.

used for data analysis (SPSS, Inc., Chicago, IL, USA).

\section{Results}

\section{The expression of HOXC9 and HOXD10 decreased in PTC}

The expression of HOXC9 and HOXD10 decreased in PTC than in paracancer tissues. The low expression rates of HOXC9 and HOXD10 in PTC tissues were $40.8 \%$ and $33.7 \%$, respectively, which were significantly higher than that of paracancer tissues $(24.5 \%$ and $16.3 \%)$, with statistically significant differences (Table 2, Figure 1).

\section{Relationship between clinicopathological features and the expression of HOXC9 and HOXD10 in PTC}

The relationship between the clinicopathological features and the expression of HOXC9 and HOXD10 was analyzed to evaluate their prognostic value as a biomarker of PTC (Tables 3,4). The low expression of HOXC9 was associated with Hashimoto's thyroiditis and lymph node metastasis $(\mathrm{P}<0.05)$. The low expression of HOXD10 was associated with extrathyroidal extension and lymph node metastasis $(\mathrm{P}<0.05)$.

\section{Correlation between HOXC9 and HOXD10 in PTC}

The co-expression rates of HOXC9 and HOXD10 was $44.90 \%$. Spearman analysis showed that the two were significantly correlated $(\mathrm{P}<0.05$, Table 5$)$. The low expression of both HOXC9 and HOXD10 was associated with lymph node metastasis $(\mathrm{P}<0.05$, Table 6).

\section{Discussion}

The incidence of thyroid cancer, particularly PTC, has markedly increased over the past years around the 


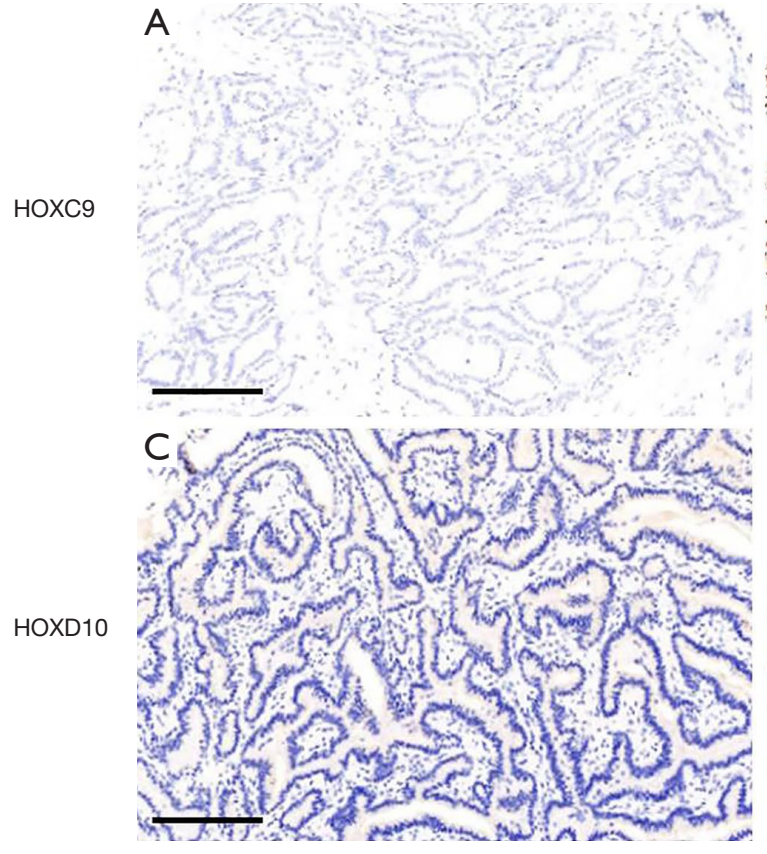

PTC tissue

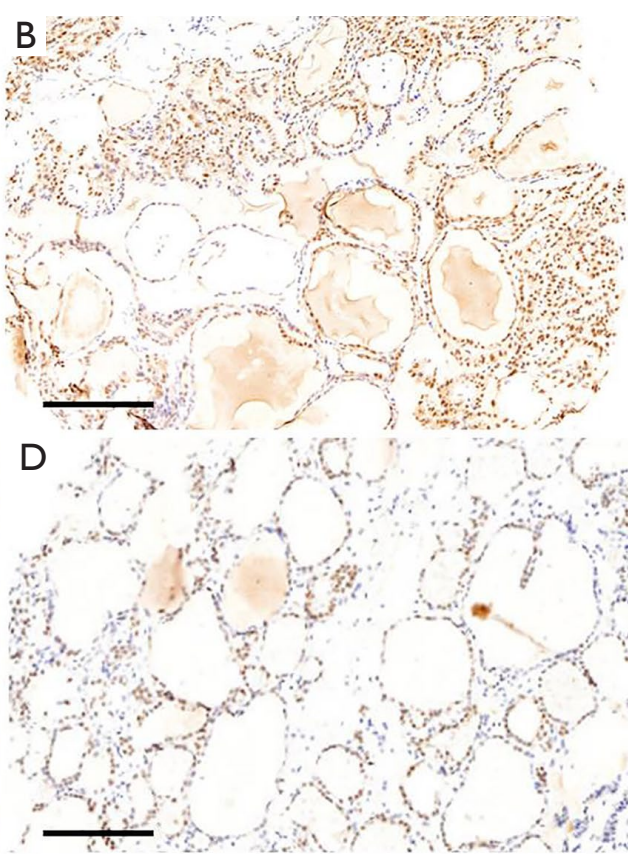

Paracancer tissue

Figure 1 Immunohistochemical detection of HOXC9 and HOXD10 in PTC and paracancer tissues. The immunostaining of HOXC9 and HOXD10 by using the antibodies against HOXC9 (1:200; Abcam, Cambridge, MA, USA) and HOXD10 (1:1,000; Abcam, Cambridge, MA, USA). The brown region indicates the immunoreactivity of HOXC9 and HOXD10 protein in the tissues. Scale bar: $200 \mu \mathrm{m}$. (A) Low expression of HOXC9 in PTC; (B) normal expression of HOXC9 in paracancer tissues; (C) low expression of HOXD10 in PTC; (D) normal expression of HOXD10 in paracancer tissues.

world (1). At the same time, the number of the patients with refractory PTC has also increased. Early diagnosis and screening of high-risk population has always been the key to the prevention and treatment of PTC. The understanding of the pathogenesis of PTC is the basis to assist clinicians in population risk assessment and early diagnosis. Appropriate biomarkers could be used to help evaluate the risk of PTC. Our previous studies had made up a genome-wide DNA methylomics database of PTC by MethylCap-Seq to find candidate biomarkers. HOXC9 and HOXD10 were found to be aberrant hypermethylated in PTC $(12,13)$. Methylation of $\mathrm{CpG}$ island in promoter region can reduce gene expression. Methylation of tumor suppressor can reduce its expression and lead to tumorigenesis. However, the expression of HOXC9 and HOXD10 and their clinicopathologic relationship in PTC were still unclear.

The HOX family plays an important role in cell differentiation and morphogenesis. The dysregulation of HOX gene may play roles in tumorigenesis. Many HOX genes (like HoxA5, HoxB13 and HoxC6) have been found to be aberrantly expressed through promoter methylation in cancers including lung cancer, breast cancer, gastric cancer and colon cancer $(8,9,19)$. Previous studies verified the decreased expression of HOXD10 in some tumors and considered HOXD10 as a candidate tumor suppressor. In vitro, re-expression of HOXD10 resulted in significant inhibition of cell survival, induction of cell apoptosis, and impairment of cell migration and invasion (16). The expression of HOXD10 is reduced/lost frequently in hepatocellular carcinoma, and it was associated with vessel cancerous embolus, tumor cell differentiation, and even 3-year survival rate (20). Decreased expression of HOXD10 promotes a proliferative and aggressive phenotype in prostate cancer (21). On the other side, several previous studies demonstrated that HOXC9 acts as an oncogene. One study in colorectal cancer showed that higher expression of HOXC9 was associated with advanced tumor stage, risk of distant metastasis, tendency for venous invasion, and even overall survival (14). The similar results were reported in gastric cancer and breast cancer $(22,23)$.

In this study, we investigate the expression of HOXC9 and HOXD10 in PTC by IHC. The expression of 
Table 3 The relationship between HOXC9 expression and clinicopathological features of PTC

\begin{tabular}{|c|c|c|c|}
\hline Clinicopathological feature & \multicolumn{2}{|c|}{ HOXC9 expression } & $P$ value \\
\hline Patients number & $58(59.2)$ & $40(40.8)$ & \\
\hline Age & & & 0.333 \\
\hline$<55$ years & $47(63.5)$ & $27(36.5)$ & \\
\hline Gender & & & 0.352 \\
\hline Male & $17(68.0)$ & $8(32.0)$ & \\
\hline Female & $41(56.2)$ & $32(43.8)$ & \\
\hline Extrathyroidal extension & & & 0.798 \\
\hline Size & & & 0.097 \\
\hline$>1 \mathrm{~cm}$ & $21(48.8)$ & $22(51.2)$ & \\
\hline$\leq 1 \mathrm{~cm}$ & 37 (67.3) & $18(32.7)$ & \\
\hline Multifocal & & & 0.642 \\
\hline Yes & $14(53.8)$ & $12(46.2)$ & \\
\hline No & $44(61.1)$ & $28(38.9)$ & \\
\hline Bilateral & & & 0.789 \\
\hline Yes & $9(56.3)$ & $7(43.8)$ & \\
\hline Yes & $26(48.1)$ & $28(51.9)$ & \\
\hline No & $32(72.7)$ & $12(27.3)$ & \\
\hline TNM stage & & & 0.338 \\
\hline I & 57 (66.3) & $29(33.7)$ & \\
\hline II & 8 (72.7) & 3 (27.3) & \\
\hline III & $0(0)$ & $1(100.0)$ & \\
\hline
\end{tabular}

Data are presented as $n(\%) .{ }^{*}$, statistically significant $(\mathrm{P}<0.05)$. PTC, papillary thyroid cancer.

HOXC9 and HOXD10 was decreased in PTC than that in paracancer tissues. Further analysis showed the low expression of HOXC9 was associated with Hashimoto's thyroiditis and lymph node metastasis $(\mathrm{P}<0.05)$. The low expression of HOXD10 was associated with extrathyroidal extension and lymph node metastasis $(\mathrm{P}<0.05)$. The coexpression rates of HOXC9 and HOXD10 was $44.90 \%$ $(\mathrm{P}<0.05)$. Both of HOXC9 and HOXD10 were associated with lymph node metastasis. The results suggested that both of them may play a role in the tumor biological behavior of 
Table 4 The relationship between HOXD10 expression and clinicopathological features of PTC

\begin{tabular}{|c|c|c|c|}
\hline Clinicopathological feature & \multicolumn{2}{|c|}{ HOXD10 expression } & $P$ value \\
\hline Patients number & $65(66.3)$ & $33(33.7)$ & \\
\hline Age & & & 0.813 \\
\hline$<55$ years & $43(58.1)$ & $31(41.9)$ & \\
\hline Gender & & & 0.809 \\
\hline Male & $16(64.0)$ & $9(36.0)$ & \\
\hline Female & $49(67.1)$ & 24 (32.9) & \\
\hline Extrathyroidal extension & & & $0.017^{\star}$ \\
\hline Size & & & 0.139 \\
\hline$>1 \mathrm{~cm}$ & $25(58.1)$ & 18 (41.9) & \\
\hline$\leq 1 \mathrm{~cm}$ & $40(72.7)$ & $15(27.3)$ & \\
\hline Multifocal & & & 0.630 \\
\hline Yes & $16(61.5)$ & $10(38.5)$ & \\
\hline No & $49(68.1)$ & 23 (31.9) & \\
\hline Bilateral & & & 0.776 \\
\hline Yes & $10(62.5)$ & $6(37.5)$ & \\
\hline Yes & $30(55.6)$ & $24(44.4)$ & \\
\hline No & $35(79.5)$ & $9(20.5)$ & \\
\hline TNM stage & & & 0.674 \\
\hline 1 & $51(59.3)$ & $35(40.7)$ & \\
\hline II & $6(54.5)$ & $5(45.5)$ & \\
\hline III & $1(100.0)$ & $0(0)$ & \\
\hline
\end{tabular}

Data are presented as $\mathrm{n}(\%)$. *, statistically significant $(\mathrm{P}<0.05)$. PTC, papillary thyroid cancer.

PTC and they may have a synergistic effect. The combined application of the two biomarkers may improve the clinical value.

Our previous studies had showed the function of HOXD10 as a tumor suppressor in PTC (12). In this study, HOXD10 was showed to be low expressed in PTC. And the low expression of HOXD10 was associated with extrathyroidal extension and lymph node metastasis. The results were consistent with the previous studies in other malignant tumors. Nevertheless, the result in HOXC9 was 
Table 5 the correlation between HOXC9 and HOXD10 expression in PTC tissues

\begin{tabular}{lccc}
\hline & & HOXC9 & Low \\
\cline { 2 - 3 } HOXD10 & High & 21 & $0.016^{*}$ \\
\hline High & 44 & 19 & \\
\hline
\end{tabular}

${ }^{*}$, statistically significant $(\mathrm{P}<0.05)$. PTC, papillary thyroid cancer.

Table 6 The relationship between clinicopathological features and the low expression of both HOXC9 and HOXD10 in PTC

\begin{tabular}{|c|c|c|c|}
\hline Clinicopathological feature & \multicolumn{2}{|c|}{ Low expression of both } & $P$ value \\
\hline Patient number & 79 (80.6) & $19(19.4)$ & \\
\hline Age & & & 1.000 \\
\hline$<55$ years & $59(79.7)$ & $15(20.3)$ & \\
\hline Male & $21(84.0)$ & 4 (16.0) & \\
\hline Female & $58(79.5)$ & $15(20.5)$ & \\
\hline Extrathyroidal extension & & & 0.517 \\
\hline Yes & $14(73.7)$ & $5(26.3)$ & \\
\hline$>1 \mathrm{~cm}$ & $32(74.4)$ & $11(25.6)$ & \\
\hline$\leq 1 \mathrm{~cm}$ & $47(85.5)$ & $8(14.5)$ & \\
\hline Multifocal & & & 0.574 \\
\hline Yes & 20 (76.9) & $6(23.1)$ & \\
\hline No & 59 (81.9) & $13(18.1)$ & \\
\hline Bilateral & & & 0.506 \\
\hline Yes & $12(75.0)$ & $4(25.0)$ & \\
\hline No & 67 (81.7) & 15 (18.3) & \\
\hline No & 40 (90.9) & $4(9.1)$ & \\
\hline TNM stage & & & 0.879 \\
\hline I & $69(80.2)$ & 17 (19.8) & \\
\hline II & 9 (81.8) & 2 (18.2) & \\
\hline III & $1(100.0)$ & $0(0)$ & \\
\hline
\end{tabular}

Data are presented as $\mathrm{n}(\%) .{ }^{*}$, statistically significant $(\mathrm{P}<0.05)$. PTC, papillary thyroid cancer. 
different in PTC from other cancers. HOXC9 was usually showed as an oncogene in other cancers, like gastric cancer and breast cancer. But in this study, HOXC9 was showed as a tumor suppressor in PTC. Cause the low expression of HOXC9 was associated with lymph node metastasis. Chronic inflammation caused by Hashimoto's thyroiditis was speculated a predisposing factor of PTC. The low expression of HOXC9 may be one of the influencing factors between PTC and Hashimoto's thyroiditis. However, no related research in PTC has been reported before. This study is just a retrospective study and only the protein expression of paraffin specimens has been detected. Further studies at higher molecular level and prospective studies are yet needed.

In summary, this study firstly researched the expression and clinicopathologic relationship of HOXC9 and HOXD10 in PTC. The expression of HOXC9 and HOXD10 decreased in PTC. And the low expression of HOXC9 and HOXD10 was associated with some clinicopathologic features. The result showed that both of them may play a role in the tumor biological behavior of PTC. And the combined application of them may improve their clinical value as biomarkers.

\section{Acknowledgments}

The authors are grateful to Qing-Hai Ji for kindly providing the administrative supports.

Funding: This work was supported by the Science and Technology Project of Shanghai Science and Technology Committee (grant no. 12ZR1406800).

\section{Footnote}

Reporting Checklist: The authors have completed the REMARK reporting checklist. Available at https://dx.doi. org/10.21037/tcr-21-373

Data Sharing Statement: Available at http://dx.doi. org/10.21037/tcr-21-373

Conflicts of Interest: All authors have completed the ICMJE uniform disclosure form (available at http://dx.doi. org/10.21037/tcr-21-373). The authors have no conflicts of interest to declare.

Ethical Statement: The authors are accountable for all aspects of the work in ensuring that questions related to the accuracy or integrity of any part of the work are appropriately investigated and resolved. The study was conducted in accordance with the Declaration of Helsinki (as revised in 2013). The study was approved by ethics board of Fudan University Shanghai Cancer Center (No.: 0504324-1911D) and informed consent was taken from all the patients.

Open Access Statement: This is an Open Access article distributed in accordance with the Creative Commons Attribution-NonCommercial-NoDerivs 4.0 International License (CC BY-NC-ND 4.0), which permits the noncommercial replication and distribution of the article with the strict proviso that no changes or edits are made and the original work is properly cited (including links to both the formal publication through the relevant DOI and the license). See: https://creativecommons.org/licenses/by-nc-nd/4.0/.

\section{References}

1. Lim H, Devesa SS, Sosa JA, et al. Trends in thyroid cancer incidence and mortality in the united states, 1974-2013. JAMA 2017;317:1338-48.

2. Liu RQ, Wiseman SM. Quality indicators for thyroid cancer surgery: Current perspective. Expert Rev Anticancer Ther 2016;16:919-28.

3. Noguchi S, Noguchi A, Murakami N. Papillary carcinoma of the thyroid. I. Developing pattern of metastasis. Cancer 1970;26:1053-60.

4. Hundahl SA, Cady B, Cunningham MP, et al. Initial results from a prospective cohort study of 5583 cases of thyroid carcinoma treated in the united states during 1996. U.S. And German Thyroid Cancer Study Group. An American College of Surgeons Commission on Cancer Patient Care Evaluation study. Cancer 2000;89:202-17.

5. Patron V, Bedfert C, Le Clech G, et al. Pattern of lateral neck metastases in N0 papillary thyroid carcinoma. BMC Cancer 2011;11:8.

6. Samuel S, Naora H. Homeobox gene expression in cancer: Insights from developmental regulation and deregulation. Eur J Cancer 2005;41:2428-37.

7. Shah N, Sukumar S. The Hox genes and their roles in oncogenesis. Nat Rev Cancer 2010;10:361-71.

8. Jung C, Kim RS, Zhang H, et al. HOXB13 is downregulated in colorectal cancer to confer TCF4mediated transactivation. Br J Cancer 2005;92:2233-9.

9. Raman V, Martensen SA, Reisman D, et al. Compromised HOXA5 function can limit p53 expression in human breast 
tumours. Nature 2000;405:974-8.

10. Rauch T, Wang Z, Zhang X, et al. Homeobox gene methylation in lung cancer studied by genomewide analysis with a microarray-based methylated CpG island recovery assay. Proc Natl Acad Sci U S A 2007;104:5527-32.

11. de Bessa Garcia SA, Araújo M, Pereira T, et al. HOX genes function in Breast Cancer development. Biochim Biophys Acta Rev Cancer 2020;1873:188358.

12. Cao YM, Gu J, Zhang YS, et al. Aberrant hypermethylation of the HOXD10 gene in papillary thyroid cancer with BRAFV600E mutation. Oncol Rep 2018;39:338-48.

13. Cao Y, Zhu Y. Screening of aberrant DNA methylation in papillary thyroid cancer. China Oncology 2019;29:780-7.

14. Hu M, Ou-Yang W, Jing D, et al. Clinical Prognostic Significance of HOXC9 Expression in Patients with Colorectal Cancer. Clin Lab 2019. doi:10.7754/Clin. Lab.2019.190122.

15. Mao L, Ding J, Zha Y, et al. HOXC9 links cell-cycle exit and neuronal differentiation and is a prognostic marker in neuroblastoma. Cancer Res 2011;71:4314-24.

16. Wang L, Chen S, Xue M, et al. Homeobox D10 gene, a candidate tumor suppressor, is downregulated through promoter hypermethylation and associated with gastric carcinogenesis. Mol Med 2012;18:389-400.

17. Carrio M, Arderiu G, Myers C, et al. Homeobox D10

Cite this article as: Cao YM, Wen D, Qu N, Zhu YX. Prognostic and clinical significance of HOXC9 and HOXD10 in papillary thyroid cancer. Transl Cancer Res 2021;10(7):33173325. doi: 10.21037/tcr-21-373 induces phenotypic reversion of breast tumor cells in a three-dimensional culture model. Cancer Res 2005;65:7177-85.

18. Wen D, Liao T, Ma B, et al. Downregulation of CSN6 attenuates papillary thyroid carcinoma progression by reducing $W$ nt/beta-catenin signaling and sensitizes cancer cells to FH535 therapy. Cancer Med 2018;7:285-96.

19. Shiraishi M, Sekiguchi A, Oates AJ, et al. HOX gene clusters are hotspots of de novo methylation in $\mathrm{CpG}$ islands of human lung adenocarcinomas. Oncogene 2002;21:3659-62.

20. Guo Y, Peng Y, Gao D, et al. Silencing HOXD10 by promoter region hypermethylation activates ERK signaling in hepatocellular carcinoma. Clin Epigenetics 2017;9:116.

21. Mo RJ, Lu JM, Wan YP, et al. Decreased HoxD10 expression promotes a proliferative and aggressive phenotype in prostate cancer. Curr Mol Med 2017;17:70-8.

22. Zhao XF, Yang YS, Park YK. HOXC9 overexpression is associated with gastric cancer progression and a prognostic marker for poor survival in gastric cancer patients. Int J Clin Oncol 2020;25:2044-54.

23. Hur H, Lee JY, Yang S, et al. HOXC9 induces phenotypic switching between proliferation and invasion in breast cancer cells. J Cancer 2016;7:768-73. 